\title{
Numerical Modeling of Welded Joints by the "Friction Stir Welding" Process
}

\author{
Diego H. Santiago ${ }^{a}$, Guillermo Lombera ${ }^{\text {a*, Santiago Urquiza }}$, \\ Anibal Cassanelli ${ }^{\mathrm{a}}$, Luis A. de Vedia ${ }^{\mathrm{b}}$

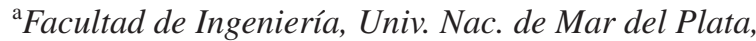 \\ J.B. Justo 4302, 7600, Mar del Plata, Bs. As., Argentine \\ ' ITPJS, Univ. Nac. De San Martín - CNEA, CIC, San Martín, Bs. As.,Argentine
}

Received: March 17, 2004; Revised: September 28, 2004

\begin{abstract}
The present work is aimed to simulate the Friction Stir Welding process as a three-dimensional thermally coupled viscoplastic flow. A Finite Element technique is employed, within the context of a general purpose FEM framework, to provide the temperature distributions and the patterns of plastic flow for the material involved in the welded joints. The computational tool presented here may be of great relevance for technologist seeking to set the process control variables, as they are intended to obtain suitable material properties that yield the adequate on service response of the structural components.
\end{abstract}

Keywords: Friction stir welding (FSW), viscoplastic modeling, three-dimensional modeling, finite elements model, aluminum butt welding

\section{Introduction}

Welding by means of the friction stir welding (FSW) process is a technique for joining two sheets or thick plates with only mechanic energy as input. In Fig. 1 we observe a schematic representation of the FSW process, the tool consists essentially in a rotating solid cylinder with a protruding screwed insert of smaller diameter (Fig. 2). The main cylinder prevents the material from being expulsed from the pieces to be welded thus preventing the formation of voids or other defects in the welded zone.

Once the pieces to be welded are presented and firmly restrained on the welding fixture, the protruding insert of the tool is forced within the pieces to be welded until the cylindrical part is in contact with the work surface. As the tool rotates and progresses along the seam, the friction heated and softened material flows around the insert towards its trailing part where it consolidates to create a solid phase high quality weld. Notice that the tool axis has typically a tilt of some degrees $\left(2^{\circ}\right.$ or $\left.3^{\circ}\right)$ with respect to the vertical, in order to facilitate the weld nugget formation.

Several papers have been written on the FSW process, Flores et al. ${ }^{1}$, Murr et al. ${ }^{2}$, Liu et al. ${ }^{3}$ and Midling about the microstructural aspects of the welded aluminum alloys and also the works of Dawes and Thomas ${ }^{4,5}$ who described the FSW process summarizing its advantages and disadvan- tages. However, although considerable experimental published works have been reported, there are relatively few papers about modeling the FSW process. Gould et al. ${ }^{6}$ developed an analytical heat flow model for FSW. The model is based on the well known Rosenthal equation ${ }^{7}$, which describes a stationary temperature field in a semi-infinite plate due to a mobile heat source. A lot of simplifications had to be introduced in order to obtain a closed solution in the temperatures field. Stewart et al. ${ }^{8}$ used an approximate energy balance to predict the weld shape and the temperatures inside the welded zone. The temperatures field was also predicted using the method developed in the reference 7. It should be stressed that because of the problem characteristics, where the plastic deformations are dominant, good results can be expected using thermomechanically coupled viscoplastic flow models ${ }^{9,10}$. In addition, due the cinematic and geometric characteristics of the process, the problem turns out to be threedimensional, which together with the existence of strong gradients in the deformation velocities around the insert, imposes a high computational demand. Recently ${ }^{9}$, scientists have entered upon this type of modeling but with some kind of limitations considering the localized densification possibilities, among other questions.

A proper description of the temperature field is a lead-

*e-mail: glombera@ fi.mdp.edu.ar 


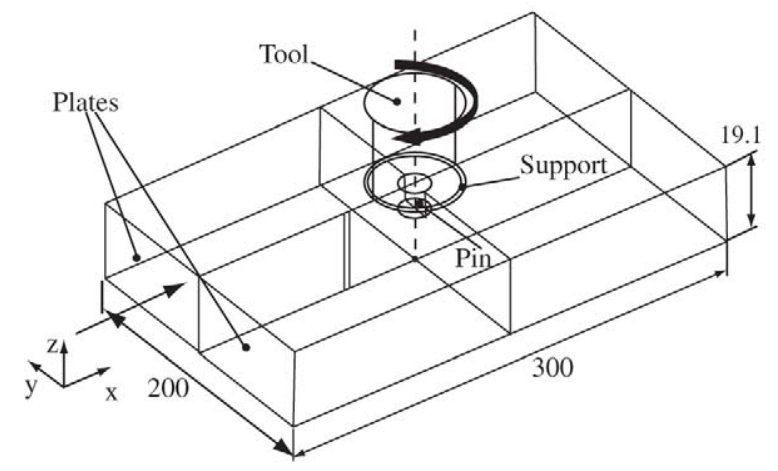

Figure 1. Schematic representation of the FSW process.
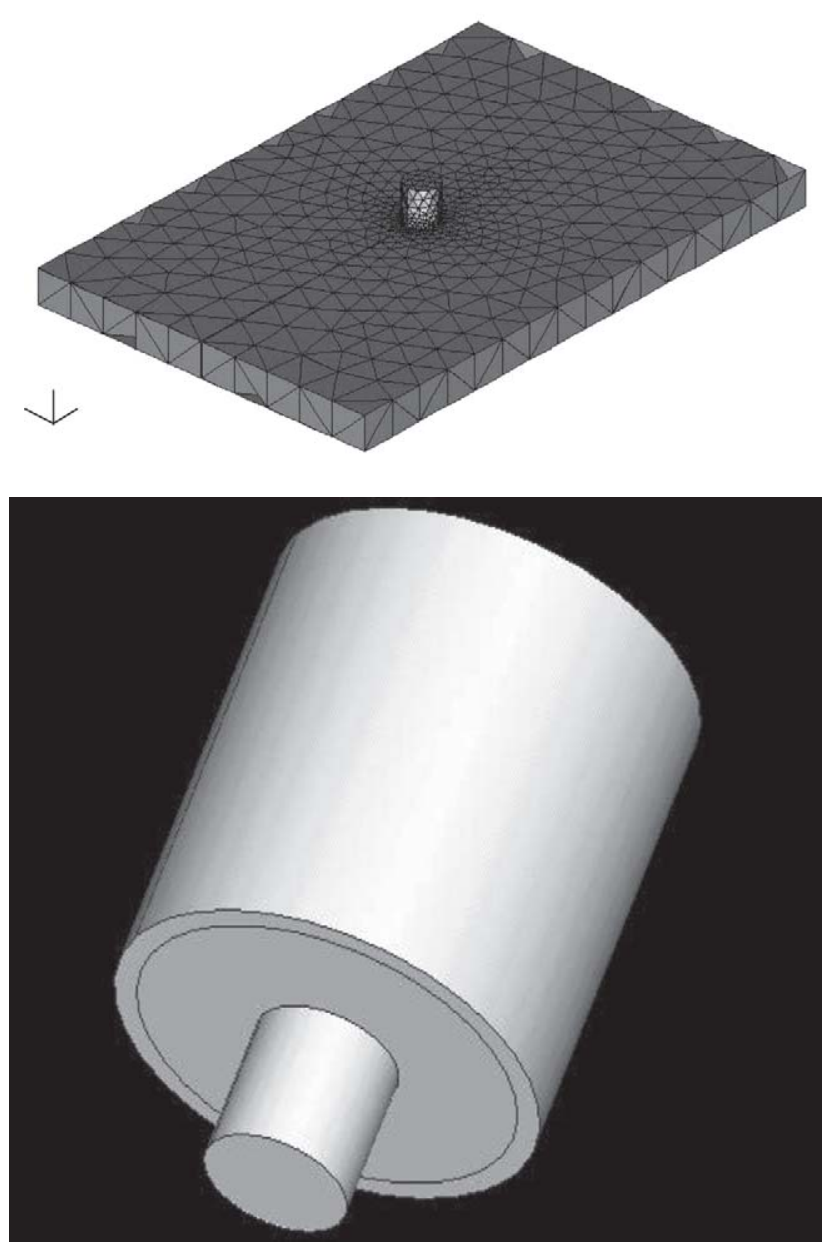

Figure 2. Tetrahedral finite element and tool sketch.

ing element when predicting the microstructural properties in the affected zone and when optimum design or improvement of the welding tools geometry are needed.

In virtue of the complex physics involved during the FSW process, the aim of the present research is to improve the process comprehension by means of numerical modeling, inquiring into the basic aspects of the process so as to determine the computational exigency level that this type of modeling requires for the adequate representation of the principal phenomena involved, towards a further sensibility analysis.

\section{Fundamental Equations}

\subsection{Mechanical model}

Leaving aside the inertial and volume forces, the equilibrium equations in a volume $\Omega$ of material with a $\partial \Omega$ boundary, can be written in the following way ${ }^{10}$ :

$$
\nabla \cdot \sigma=0 \text { en } \Omega
$$

where $\sigma$ is the Cauchy stress tensor.

The deformation rate vector is related to the symmetric part of the velocities field gradient according to:

$$
\mathbf{D}=\frac{\left(\nabla \mathbf{u}^{\mathrm{T}}+\nabla \mathbf{u}\right)}{2}
$$

Assuming the material as incompressible, the continuity equation must be satisfied for the whole dominion $\Omega$ :

$$
\nabla \cdot \mathbf{u}=0
$$

If we adopt a flow formulation for modeling the large plastic deformations involved in the stir-welding process, the stress deviator tensor $\mathbf{S}$ can be related to deformation rate tensor $\mathbf{D}$ - which is actually a deviator in virtue of the incompressibility - by the following relation:

$$
\begin{aligned}
& \mathbf{S}=2 \mu \mathbf{D}, \mathbf{S}=\sigma-p \mathbf{I} \\
& \mu=\frac{\sigma_{\mathrm{e}}}{3 \varepsilon_{\mathrm{e}}}
\end{aligned}
$$

where $\mu$ is the effective viscosity of the material and $p$ the hydrostatic pressure. Besides, $\sigma_{\mathrm{e}}$ is the effective stress or the second stress invariant and $\varepsilon_{\mathrm{e}}$ is the effective deformation rate or the second invariant of the deformation rate.

In this work it was assumed a rigid and viscoplastic material where the flow stress depends on deformation rate and temperature. This is represented by the following relation $^{11}$ :

$$
\sigma_{\mathrm{e}}=\frac{1}{\alpha} \arg \operatorname{Sh}\left[\left(\frac{Z}{A}\right)^{1 / n}\right], \text { con } Z=\varepsilon_{\mathrm{e}} \exp \left(\frac{Q}{R T}\right)
$$

where $\alpha, Q, A$ and $n$ are material constants, $R$ is the ideal gas constant and $T$ is the absolute temperature.

The material constants can be determined using standard compression tests. The mechanical model is completed after describing the appropriate boundary conditions.

\subsection{Thermal model}


The temperatures distribution is obtained by solving the heat balance equation ${ }^{10}$ :

$$
\rho C p \frac{D \theta}{D t}=\nabla \cdot(k \nabla \theta)+\gamma
$$

where $\rho$ is density, $\mathrm{Cp}$ the heat capacity, $\mathrm{k}$ the thermal conductivity, $\theta$ the temperature and $\gamma$ the inner rate of heat generation by dissipation of viscoplastic power.

It is assumed that about $90 \%$ of the plastic power is transformed into heat. The term corresponding to the heat generation rate by mechanical work can be expressed as the contracted product of stress with deformation rate, as follows:

$$
\gamma=\eta \mathbf{S}: \mathbf{D}
$$

where $\eta$ is the power fraction which is not absorbed by microstructural defects.

Properties of pure aluminum where adopted for the mechanical parameters as well as for the temperature dependent conductivity and specific heat.

\subsection{Geometric model}

In the present study it is assumed a reference framework fixed to the welding tool, in such a way that the plate moves towards it with a fixed velocity $(1.05 \mathrm{~mm} / \mathrm{sec})$ and with an initial temperature $\left(25^{\circ} \mathrm{C}\right)$ both imposed in the leading surface of the zone to be studied.

Since the tool insert surface is mechanized with a helical shape, the effect of running down flow produced for such geometry is simulated imposing a running down velocity component at the insert surface. This velocity is a function of the advancing speed of the insert $(1.067 \mathrm{~mm} /$ revolution) and of the rotation rate of the tool (11.7 revolutions/sec)

Material data and other parameters from the model are included in the Tables 1 to 3 .

\subsection{Numerical modeling}

Table 1. Thermal Property.

\begin{tabular}{ccc}
\hline Property & Steel Tool & Aluminum Plates \\
\hline$\rho\left[\mathrm{Kg} / \mathrm{m}^{3}\right]$ & $7.810^{3}$ & $2.710^{3}$ \\
$\mathrm{Cp}\left[\mathrm{J} / \mathrm{Kg}{ }^{\circ} \mathrm{C}\right]$ & $0.510^{3}$ & $1.0510^{3}$ \\
$\mathrm{k}\left[\mathrm{W} / \mathrm{m}^{\circ} \mathrm{C}\right]$ & 40.0 & 207.0 \\
\hline
\end{tabular}

The base plate was modeled with a finite tetrahedral element netting of the Taylor-Hood type ${ }^{10}$, that is tetrahedrons P2-P1, with quadratic interpolations for velocities and lineal interpolations for stresses, so as to get stability from stresses interpolations for the null divergence condition together with an appropriate capture of the stress gradients in boundary layers. The netting used had approximately 10200 elements with 15500 velocity nodes (Fig. 2).

The resolution algorithm consists of two steps: in the first one the velocities field is obtained assuming a fixed temperatures field. There is an iteration made by successive replacements in order to produce a non-linear adaptation of the viscosity values according to deformation rates obtained in the previous iteration. The discrete equations are obtained from the classical formulation of the Stokes problem for totally incompressible viscous flow and according to the interpolations above mentioned, adding the artificial pseudocompressibility of Chorin ${ }^{12}$. The linear equations system for each iteration is solved by the conjugated square gradients with a preconditioner of incomplete factorization of type LU according to the scheme proposed by Y Saad and Sparse $^{13}$. In the second step the temperatures field is solved with quadratic interpolation as a problem of convectiondiffusion assuming the velocities field obtained in the first step. The numerical solving method is the same as in the first step.

Although the stationary solution is required, an advancethrough-time scheme totally implicit was used fundamentally as a preconditioner of the equations system.

\section{Results}

\subsection{Velocities field}

In the results no tool graphic is shown in order to make easier the visualization of data in Figs. 3, 4 and 5.

Figure 3 shows flow lines of the material in the insert region of the tool. It is clearly observed the running-down effect that produces the grooving of the surface. It is also

\begin{tabular}{|c|c|c|c|c|}
\hline Material & A & $\alpha\left(\mathrm{mm}^{2} \mathrm{~N}^{-1}\right)$ & $\mathrm{n}$ & $\mathrm{H}\left(\mathrm{J} \mathrm{mol}^{-1}\right)$ \\
\hline Alloys 1S & $0.22410^{13}$ & 0.052 & 4.54 & 177876.4 \\
\hline
\end{tabular}

Table 3. Viscosity Law Parameters.

Table 2. Dimensions of the tool and the aluminum plate.

\begin{tabular}{cccc}
\hline (mm) & Steel Tool & (mm) & Aluminum Plates \\
\hline Pin Diameter & 6.4 & Long (dimension in X axis) & 100 \\
Pin High & 6.4 & Width (dimension in Y axis) & 60 \\
Support Diameter & 19 & Thick (dimension in Z axis) & 19.1 \\
Support High & 20 & & \\
\hline
\end{tabular}


seen how the material stays close to the insert surface during several rotations of the tool before following its course in the welding direction.

Figure 4 shows the velocity module in planes $\mathrm{XZ}$ and YZ that go through the center of the tool insert. It can be observed a strong boundary layer in the insert surface.

\subsection{Temperatures field}

The temperatures field and material velocities are shown in Fig. 5. It is clearly observed that the heat is concentrated at the insert surface, where the largest deformation rates are produced, and as a consequence, the greatest heat generation.

Figure 6 shows sections in planes $\mathrm{XZ}$ and $\mathrm{YZ}$ respec-

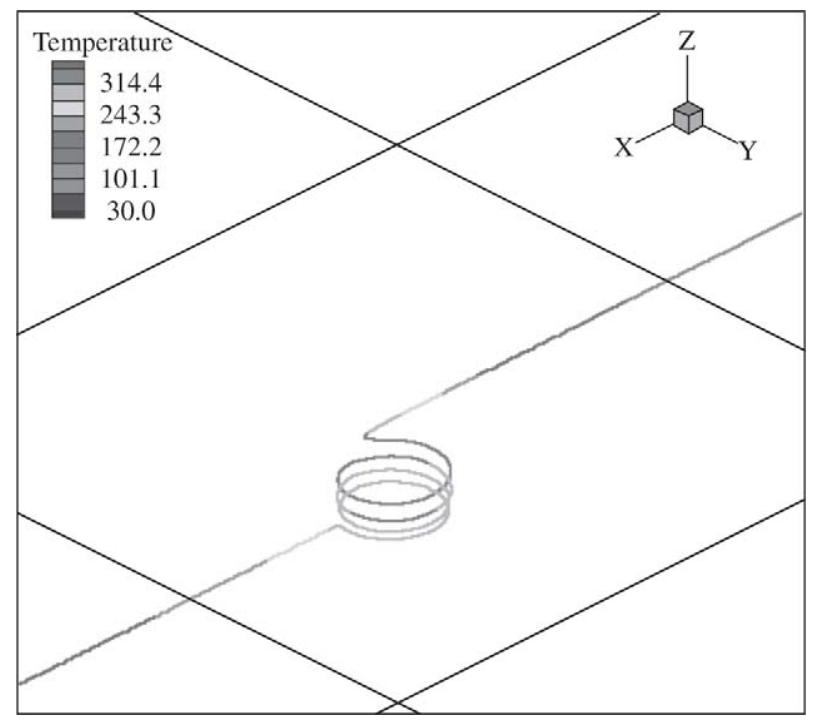

Figure 3. Flow lines of the material in the insert region of the tool.

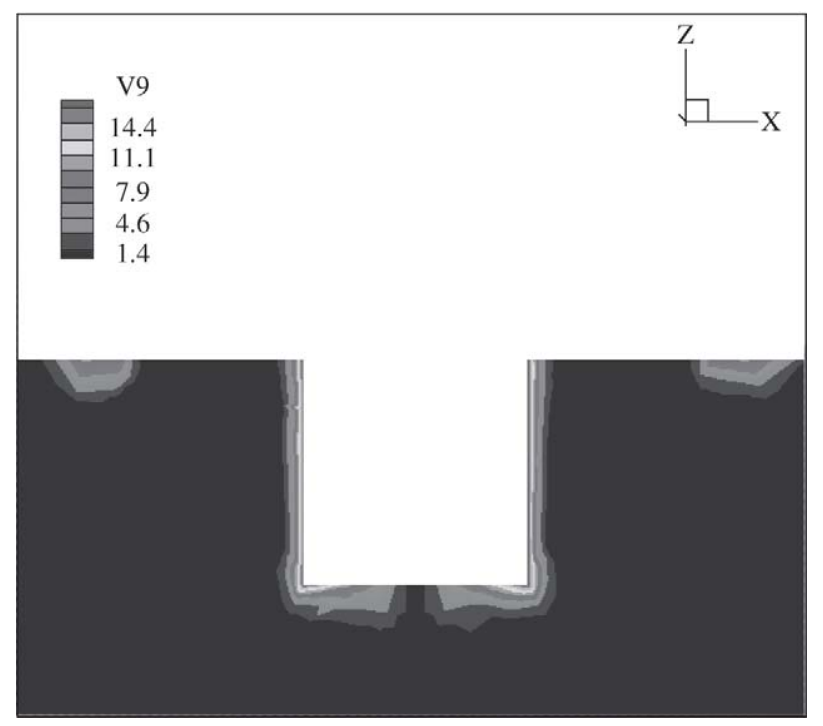

Figure 4. Velocity module in planes $\mathrm{XZ}$ and $\mathrm{YZ}$. tively, from temperatures field of the above figure. In plane $\mathrm{XZ}$ is observed the convective dragging effect on the temperatures field produced by the welding speed. In the temperatures field showed in plane $\mathrm{YZ}$ is observed a higher temperature in the right side of the insert, as in this side the tangent velocity direction in the insert opposes to the welding velocity direction. In Fig. 7 experimental results are compared to those obtained in the simulation. The abscises axis are the tool position in the welding direction, were zero position is the tool center. This data is taken $12.7 \mathrm{~mm}$ from the interface between plates. The experimental data is obtained from the reference 9 .

\section{Conclusions}
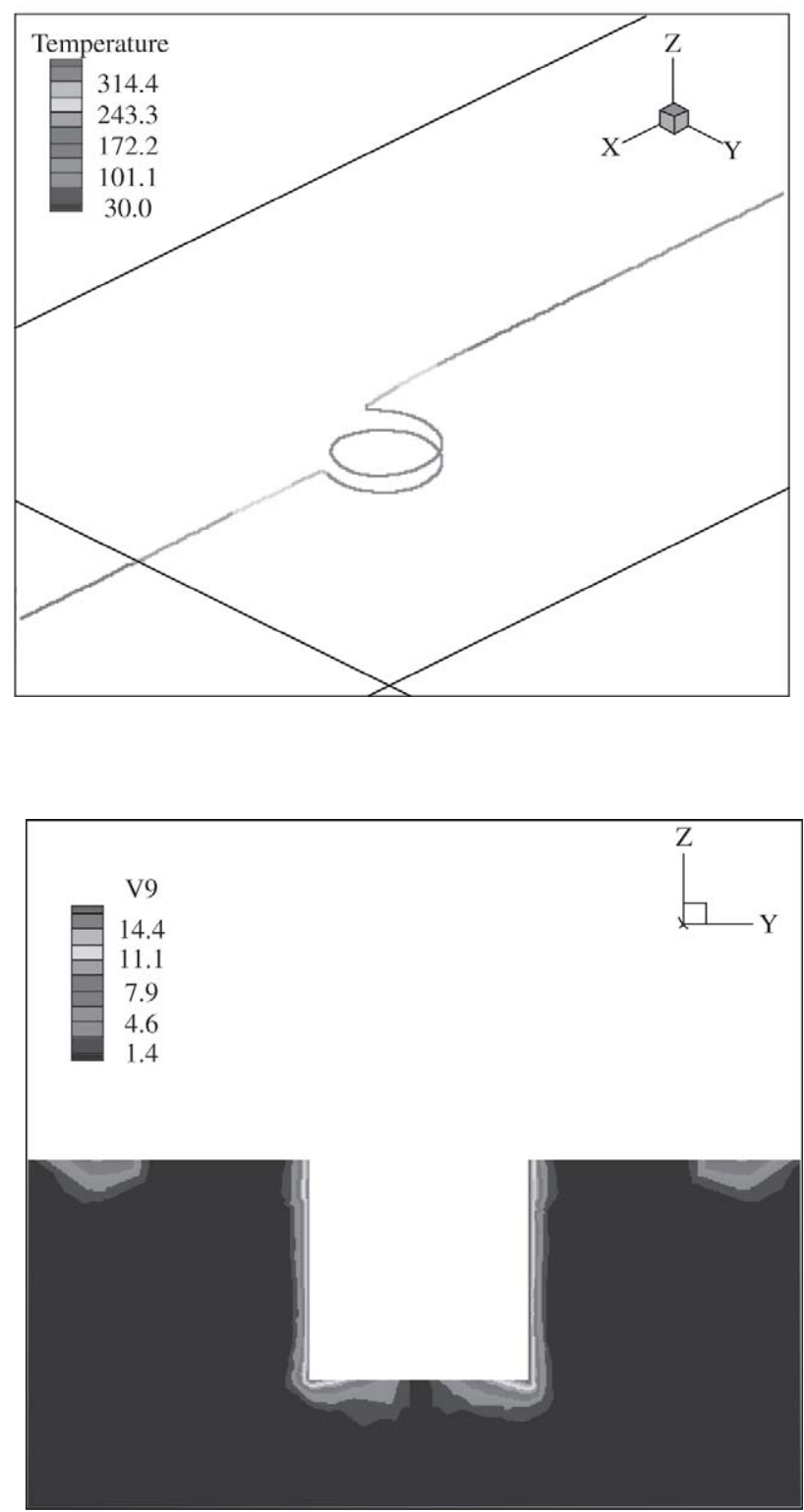


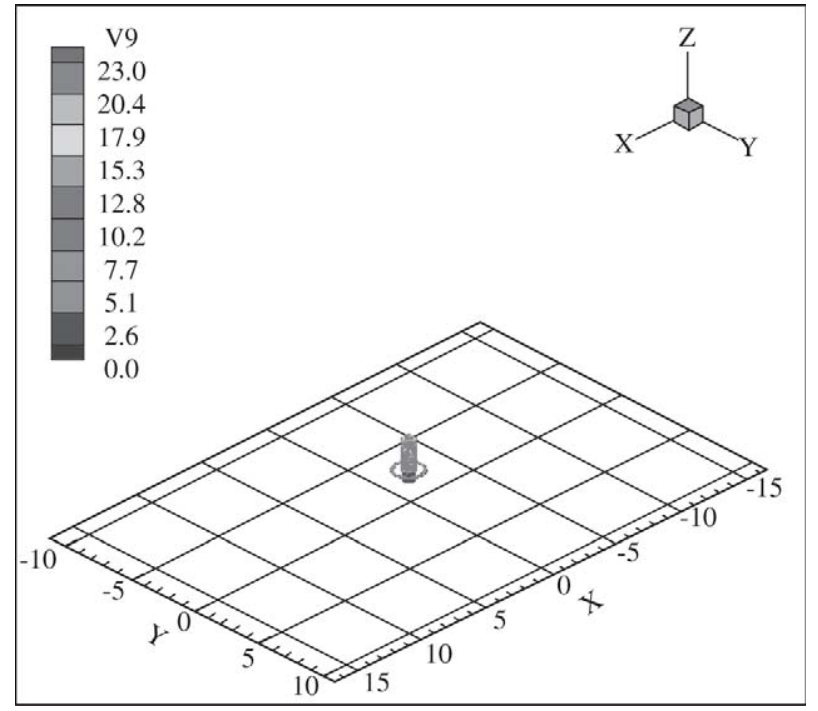

Figure 5. Material velocities and temperatures field respectively.

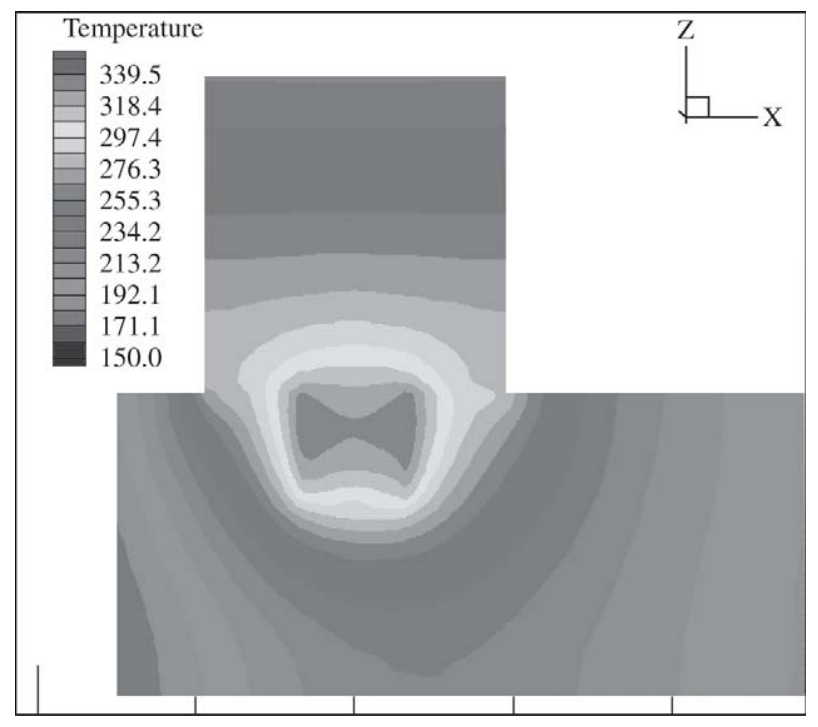

Figure 6. Temperatures field in planes $\mathrm{XZ}$ and $\mathrm{YZ}$ respectively.

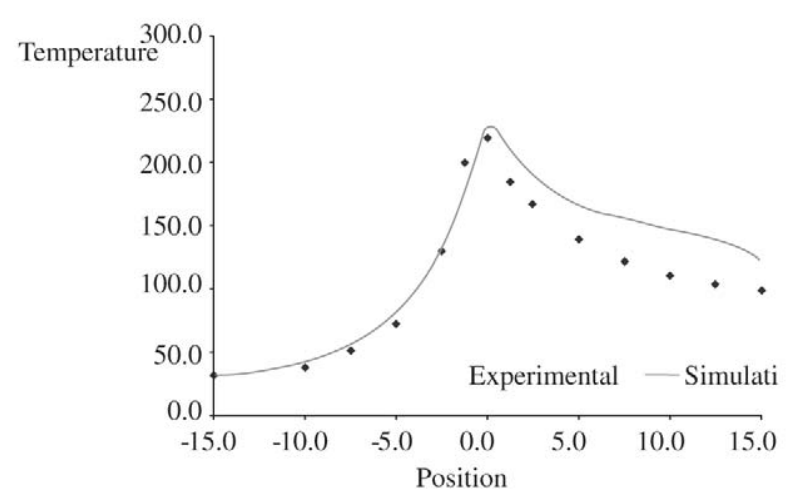

Figure 7. Experimental results compared to obtained in the simulation.
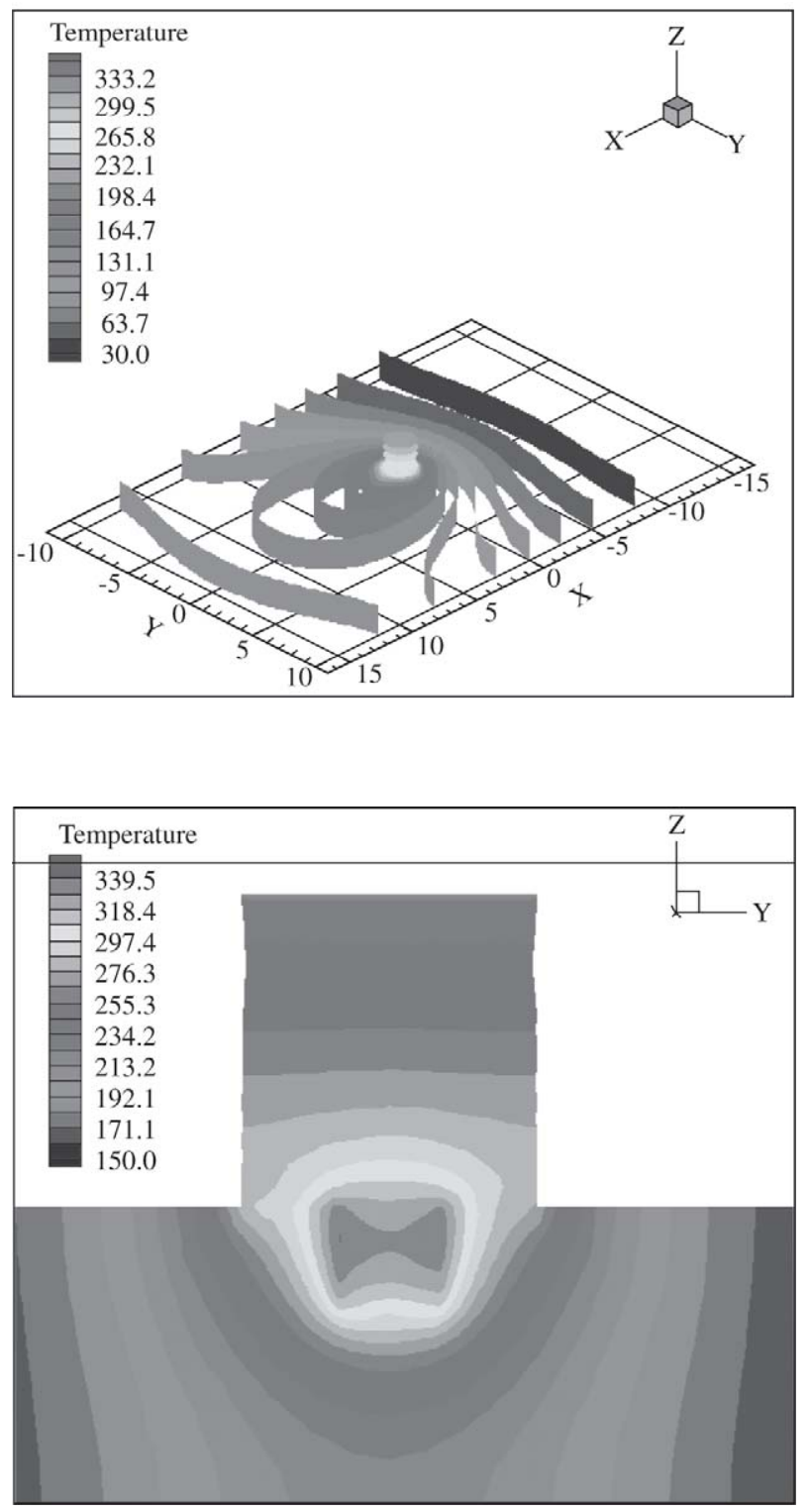

A computational three-dimensional finite element model of the FSW process was presented so as to describe the main aspects of the process and to show and evaluate the computational requirements needed for the appropriate capture of the main phenomena involved. The results obtained are fitting with those reviewed in literature. The presence of very strong gradients in the velocities field in the surroundings of the tool insert were found which requires a re-evaluation of the densifications used in such areas and towards further sensibility analysis so as to obtain nets optimally suited with the problem requirements and optimized from the computational cost point of view.

\section{References}


1. Flores, O.V.; Kennedy, C.; Murr, L.E.; Brown, D.; Pappu, S.; Nowak, B.M.; McClure, J. Microstructural issues in a friction-stir welded aluminum alloy, Scr. Mater, v. 38, p. 703, 1998.

2. Murr, L.E.; Liu, G.; McClure, J.C. A TEM study of precipitation and related microstructures in friction-stirwelded 6061 aluminum, J. Mater. Sci., v. 33, p. 1243, 1998.

3. Liu, G.; Murr, L.E.; Niou, C.S.; McClure, J.C.; Vega, F.R. Micro- structural aspects of the friction-stir welding of 6061-T6 aluminum alloy, Scr. Mater, v. 37, p. 335, 1997.

4. Dawes, C.J.; Thomas, W.M. Friction stir process for aluminum alloys, Welding J. v. 75, p. 41, 1996.

5. Dawes, C.J. An introduction to friction stir welding butt welding and its developments, Welding and Fabrication Jan, 1995.

6. Gould, J.E.; Feng, Z. Heat flow model for friction stir welding of aluminum alloys, Journal of Material Processing and Manufacturing Science 7, 1998.

7. Rosenthal, D.; Schemerber, R. Thermal study of arc weld- ing, Welding J., v. 17, 208s, 1938.

8. Stewart, M.B.; Adams, G.P.; Nunes, A.C.; Romine, P. A combined experimental and analytical modeling approach to understanding friction stir-welding, Developments in Theoretical and Applied Mechaninics, SECTAM XIX, p. 472, 1998,

9. P. Ulysse. Three-dimensional modeling of the friction stir-welding process International Journal of Machine Tools and Manufacture, v. 42, p. 1549-1557, 2002.

10. Zienkiewicz, O.C.; Taylor, R.L. (Eds.), The Finite Element Method, fourth ed., McGraw-Hill, UK, p. 2, 1991.

11. Sheppard, T.; Wright, D.S. Determination of flow stress: Part 1 constitutive equation for aluminum alloys at elevated temperatures, Metals Technology, June, p. 215, 1979.

12. Chorin A.J. Math. Comp, v. 22, p. 745-762, 1968.

13. Saad Yuocef, SPARSEKIT: a basic tool kit for sparse matrix computation, version 2, University of Illinois, http://www.users.cs.umn.edu/ saad/software/ SPARSKIT/sparskit. html, 1994. 